\title{
Expatriates And Knowledge Transfer: A Case Study Of A Power Plant Constructed In Africa
}

\author{
S.Y. Ravu, Sandton, South Africa \\ K.M. Parker, Durban University of Technology, South Africa
}

\begin{abstract}
This paper outlines aspects of a broader exploratory study on the management of skills shortages at a leading energy utility in Africa. Specifically, the paper examines the opinions of local and foreign personnel employed on a power plant construction project on the nature of skills shortages experienced at the energy utility, the organization's short-term strategy of dealing with the shortages by employing expatriates and the latter's role in knowledge transfer. Various human resources approaches were explored to provide appropriate theoretical structure to the research including intellectual capital and human capital models. A sample of highly skilled personnel defined as "key job families" according to the Kaplan and Norton (2004) human capital model were purposively selected for the study. Primary data was collected using a questionnaire and semi-structured interviews. International research on expatriates' impact on knowledge transfer within the public sector environment is very scarce; this is the first research of its kind to examine these issues at a public power plant. Preliminary results indicate that the type of knowledge, willingness to learn and share on the part of both expatriates and locals, and national culture are some of the factors impacting the success of knowledge transfer from expatriates to locals.
\end{abstract}

Keywords: Knowledge Transfer; Human Capital; Expatriates; Power Plant

\section{INTRODUCTION}

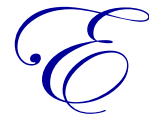
lectricity is essential for economic growth and the development of commerce and industry, and is also seen as a basic need that has sometimes been denied to specific segments of the population under different African regimes. (Department of Energy 2012). This paper describes the opinions and attitudes of key personnel employed on a power plant construction project (henceforth referred to as Project $\mathrm{X}$ ) regarding training and knowledge transfer on the Project, and the employment of expatriates to work on the Project. The paper is organised as follows: first, various theoretical underpinnings will be explored in an attempt to ground the empirical study. These include Intellectual Capital theory, specifically the focus on human capital and the contribution of organizational culture and climate to knowledge transfer (Kaplan and Norton 2004). Given that the organization has chosen to employ expatriates as a short-term policy of dealing with the skills shortages, a brief overview is given of the literature on expatriate knowledge transfer. Next, the methodology and the instruments used to conduct the empirical study will be explained, followed by a discussion of the main findings of the study. The paper concludes with an analysis of and recommendations on the organization's human resources management (HRM) policy to deal with skills shortages in the long term.

\section{LITERATURE REVIEW}

\subsection{Knowledge and Knowledge Management}

There are various definitions of what constitutes "knowledge" and "knowing". The dominant typology in the business literature (and which is relevant for the current study) is that of tacit and explicit knowledge. Whereas 
explicit knowledge deals with objective, rational and technical knowledge, tacit knowledge usually derives from personal, cognitive and experiential learning (Gupta, Iyer and Aronson 2000). As such, explicit knowledge is more easily documented, preserved, and hence transferred within an organization (Nonaka 1991). However, tacit knowledge resides in the individual employee and manifests in human behaviour. Michael Polyani in his 1962 seminal work, The Tacit Dimension said, "we can know more than we can tell." There is a growing realisation therefore that the wealth of tacit knowledge inside people's heads and embedded in the way they operate, has to be nurtured and shared so that when they leave the organization, the knowledge does not disappear; this is seen in the rapid evolution of the field of knowledge management (McAdam and McCreedy 1999).

This research finds commonalities with the intellectual capital theory of organizations. Intellectual capital may be defined as knowledge that has been transformed into an asset (Kok 2005). The Intellectual Capital (IC) approach to knowledge management (KM) focuses on the stocks and flows of intellectual capital (knowledge assets) embedded in an organization (Reed, Lubatkin and Srinivasan 2006) and which are argued to impact on its financial performance (Youndt et al. 2004 cited in Reed et al. 2006). Thus KM encompasses the processes and practices used by organizations to leverage their intellectual capital and thereby share best practices for the benefit of the entire organization (Martin 2003). Several writers (Edvinsson 1997; Sveiby 2001) identify the following as core components of IC: human capital (the knowledge created by and embodied within an organization's employees) and structural capital (the infrastructure and relationships that support human capital). Other writers further differentiate the relationship (or social) aspect of structural capital into internal (Leana and van Buren 1999; Nahapiet and Ghoshal 1998) and external dimensions (Bontis 1996).

It is the internal social capital dimension of IC theory that this paper draws upon, viz. the relationships between supervisors and employees, or between employees themselves, that influence the "sharing" of human capital within the organization. The basis of any effective KM policy is knowledge sharing. Syed-Ikhsan and Rowland (2004a) stress that effective knowledge transfer requires the willingness of a group or individual to work with others and to share that knowledge. Hence knowledge transfer will not occur unless individuals or teams display a high degree of co-operation and trust, and any KM policy must take cognisance of this. At the same time, tacit knowledge is difficult to transfer as it can be idiosyncratic to specific contexts, people, technologies and so forth (Argote 1993 cited in Syed-Ikhsan and Rowland 2004a). Value is added in an organization when there is an atmosphere of trust and motivation for people to share and use knowledge, systems and processes are in place to create and find knowledge, and appropriate technology exists to store, locate and disseminate knowledge when required (Cong and Pandya 2003).

\subsection{Human Capital Theory}

This study draws on the principles underlying Kaplan and Norton's (2004) theory of human capital which was identified as the most appropriate given the research objectives and the empirical context of Project X. The basic premise of Kaplan and Norton's theory is that an organization's strategy is intrinsically linked to its IC. Hence the measurement of IC is in essence a test of how well it is aligned to the overall strategy of the organization: if the organization has a sound strategy and the IC is aligned to that strategy, then it will add value to the organization. The model identifies three categories of IC, viz. human capital, information capital and organizational capital. Human capital (HC) refers to employees' skills, knowledge and talents; information capital describes the technological infrastructure for storing and disseminating knowledge, e.g. databases, networks etc.; and organizational capital (OC) refers to an organization's culture (Kaplan and Norton 2004). The HC and OC aspects of the theory are pertinent in this study.

Identifying the core group(s) of employees (the so-called strategic job families) that have the greatest impact on determining whether an organization attains its strategic objectives is central to determining the HC "readiness" of the organization. The issue then is whether these job families possess the requisite explicit and implicit knowledge and skills. An organization's HC readiness is measured by the difference between the existing skills base and that necessary for attaining the strategic objectives, viz. the competency gap. The model recommends that human capital development activities in the organization should be focused on the job families rather than attempting to train and develop the entire workforce. 
Organizations with strong OC and that were the most successful in attaining their strategic objectives had a culture in which all personnel within the organization were aware of and had internalised the mission, vision, and core values needed to execute the organization's strategy. Organizational culture refers to "the symbols, myths and rituals embedded in the group consciousness (or subconscious)" (Kaplan and Norton 2004: 60). OC is influenced by the extent to which an organization's leadership was able to mobilise and align employees to the strategic objectives, and whether a spirit of common interest and teamwork prevailed. OC readiness also depends on the climate within the organization, viz. the way in which organizational policies, practices and procedures, both formal (e.g. promotion and incentives structures) and informal (e.g. perceived warmth of management) influence employees' motivation and behaviour. Hence the four pillars upon which OC readiness depend are organizational culture, leadership, alignment and teamwork within the ambience of the existing organizational climate.

\subsection{Knowledge Transfer Within the Public Sector}

Although a rich literature exists on $\mathrm{KM}$ and knowledge transfer within the private sector, very little research has been done on how public sector workers perceive the sharing and management of IC (Sandhu, Jayne and Ahmad, 2011). Syed-Ikhsan and Rowland's (2004a) study of employees within the Ministry of Entrepreneur Development in Malaysia found a positive relationship between a knowledge sharing organizational culture, the availability of and access to knowledge assets and knowledge transfer. Surprisingly, there was no statistically significant correlation between employee education and training and knowledge transfer and creation of knowledge assets. In Yao, Kam and Chan's (2007) study, younger professionals working in the Hong Kong SAR government were found to be more open-minded and willing to share knowledge.

Another study by Syed-Ikhsan and Rowland (2004b) located within the same Malaysian Ministry noted that there was no specific KM strategy in place although much knowledge was embedded within the Ministry's policies and procedures. Less than half of the study participants believed that KM should be the responsibility of all employees, and not limited to top management. Sandhu et al's (2011) study found that employees believed that knowledge sharing enhanced competitive advantage, but that KM policies were not effectively communicated. Organizational barriers to knowledge sharing included lack of incentives and rewards, and insufficient information technology (IT) support. Management support of knowledge sharing and a structured KM policy were identified as crucial in several studies (Ritter and Choi 2000 cited in Yao et al. 2007; Sandhu et al. 2011; Yao et al. 2007)

Respondents in Sandhu et al's (2011) study showed self-serving bias regarding sharing of knowledge, i.e. an attitude of individualism over the group. Earlier studies by Liebowitz and Chen (2003) and Schmetz (2002), cited in Yao et al. (2007) likewise concluded that public sector employees were reluctant to share knowledge because they believed that "knowledge is power" and was the stepping stone to promotion and advancement over their colleagues. A study by Ahmad, Sharom and Abdullah (2006) found that individual motivation to share knowledge was strongly correlated to knowledge sharing behaviour amongst middle and senior managers. However the hypothesis of a negative relationship between individualism and knowledge transfer was not supported in SyedIkhsan and Rowland (2004a). Yao et al. (2007) observe that public sector employees may support a KM policy that is perceived to contribute to an organization's overall goals and missions. Chiem (2001) noted that public sector workers will engage in knowledge sharing because "they believe in the sense of social good" (cited in Yao et al. 2007).

McAdam and Reid (2000) compared the views of public sector employees with those in the private sector on selected KM dimensions. They found that public sector employees placed greater emphasis on political issues, values, education and training and formal discussions for transferring knowledge. Informal discussions were the most conducive for sharing tacit knowledge and hence socialisation and an organizational climate of co-operation and trust are important. Senior management was perceived to play a more structured role in the entire KM process within public organizations. Similar results were reported in Yao et al. (2007) where most knowledge transfer occurred mainly through informal networks, during lunch hours and after- work socialising. However, faced with budget cuts and heavier workloads, many public sector workers do not have the time to share knowledge (Yao et al. 2007). 
Yao et al. (2011) and Al-Karaghouli, Alshawi and Fitzgerald (2005) cited in Yao et al. (2011) note that national culture may also impact on knowledge sharing behaviour and KM policy. For example, Asian organizations place greater emphasis on individual tacit knowledge transfer and face to face, collaborative engagements compared to US organizations that rely more on IT to collect and disseminate knowledge. Yiu and Lin's (2002) research in Taiwanese companies concluded that the collective Chinese culture facilitated informal sharing of knowledge (cited in Yao et al. 2011). At the same time, a culture of passivity, and reluctance to question or criticize, which may describe certain Asian behaviours, is not conducive to knowledge sharing (Ritter and Choi 2000 cited in Yao et al. 2011). Yao et al. (2011) found that the Chinese culture had a somewhat negative impact on knowledge sharing to the extent that this was considered as "showing off" or impolite. Some respondents in the same study suggested that Western cultures, in particular the British culture, were more open to knowledge sharing relative to Chinese culture.

\subsection{The Role of Expatriates in Knowledge Transfer}

The term "expatriates" refers to individuals who are transferred outside their native country to another country, described as the "host" country, specifically for employment purposes (Edström and Galbraith 1977 in Hocking, Brown and Harzing 2004). Expatriates are often sent for the primary purpose of transferring explicit knowledge and if possible, tacit knowledge on-the-job (Smith 2004). A common longer term strategic objective of this training role is to replace expatriates with suitably trained locals within a designated time frame (Franko 1973; Welch, Fenwick and De Cieri 1994 cited in Smith 2004). Much of the literature on the role of expatriates in knowledge transfer has focused on their employment in multinational corporations (MNCs) and the so-called adjustment process that determines whether the international assignment is successful (Kraimer, Wayne, and Jaworski 2001; Shaffer, Harrison, Gregersen, Black, and Ferzandi 2006; Takeuchi 2010). Successful deployment implies effective knowledge transfer from the parent to the subsidiary, and hence value added to the organization.

Empirical studies on the role of expatriates in public sector knowledge transfer are virtually non-existent. According to the Manpower Talent Shortage Survey (2011), African countries faces a shortage of skilled trades workers, engineers and technicians - all skills that are essential to high-tech power station construction projects hence the need to import these skills. The organization in this research therefore formed a partnership with an MNC for the construction of Project X. All the expatriates working on Project $\mathrm{X}$ are permanently employed by or contracted to the MNC. The first confounding issue in this study therefore is that the traditional model of MNC parent/subsidiary upon which the bulk of expatriate knowledge transfer research is based does not translate to the present research. Moreover the organization's KM policy of employing expatriates is premised upon a unidirectional knowledge transfer from the foreign workers to the locals. Yet knowledge transfer occurs in multiple directions (Miesing, Kriger and Slough 2004). Further, successful knowledge transfer and management are contingent upon individual and team dynamics (Goh 2002; Davenport and Prusak 2000 cited in Syed-Ikhsan and Rowland 2004b).

The second issue which exacerbates identifying an appropriate theoretical basis for the current study is that MNCs are profit-motivated. The organization is a state-owned enterprise (SOE), funded by the tax payer, whose mandate is to provide affordable power to the general population. However, as suggested by Pan and Scarbrough (1999 cited in Ahmad et. al, 2006) for non-profit organizations such as the government, knowledge sharing is a mechanism for continuous performance improvements. An effective KM policy should add value to any organization and this could be interpreted within the context of the energy utility's service-delivery mandate.

As noted earlier, the bulk of research in this field seeks to identify the determinants of successful expatriate knowledge transfer within MNCs. Expatriate willingness or motivation to share knowledge may impact knowledge transfer (Gupta and Govindarajan, 2000; Steensma and Lyles, 2000).Smith (2004) found that American expatriates exhibited willingness to transfer knowledge. Some early research suggested that these attributes may not normally be evident in expatriates since they are focused on their own careers, and hence the importance of a systematic mentoring system to ensure that knowledge transfer does take place (Rogers 1999; Wong and Law 1999). However, Samet (2013) notes that expatriates transfers knowledge to their colleagues in developing countries, which in turn improves that country's economy. Further, Ngongo et al (2013) found that mentoring from outgoing expatriate supervisors empowers the local supervisors to perform. This builds valuable managerial capacity and skills. 
Regarding the types of knowledge that may be transferred from expatriates to locals, Smith (2004) found that most of the knowledge sharing was explicit in nature. Practical examples and hands-on knowledge sharing were more important since there were sometimes differences in understanding of industry terminology between expatriates and host country employees. However, Bonache and Brewster (2001) found that expatriate managers at a Spanish financial institution were effective in transferring mainly tacit knowledge. Riusala and Smale's (2007) study reported similar findings for accounting and finance personnel, thus implying possible interaction effects between type of knowledge, discipline-specific knowledge and knowledge transfer. Nohria and Ghoshal (1997) found that the tacit knowledge and experience of an expatriate could be transferred to the locals through a process of trial-anderror learning. Smith (2004) notes the importance of socialization and face to face interaction in the transfer of tacit knowledge. Knowledge sharing can only be effective if the cultural background is understood. Awang-Rozaimie $e t$ al (2011) confirms that lack of cultural understanding may lead to uncertainty and communication problems. Hence an expatriate, who has prior experience working with people from various and different cultural backgrounds, can share knowledge and skills successfully more easily.

Competency in managerial and technical skills are key attributes required in successful expatriate assignments, and therefore in knowledge transfer. Bjorkman and Schapp's (1994) study on western expatriates working in China found that Chinese employees were more willing to learn from expatriates possessing superior managerial and technological skills. Moreover, those expatriates perceived as not professionally competent were resented for their high salaries thus hindering knowledge transfer. Delios and Bjorkman (2000), Tsang (2001) and Wang, Tong and Koh (2004) conclude that the greater the knowledge and skills possessed by expatriates, the greater the knowledge transfer to locals. Finally, Bonache and Brewster (2001) observe that the greater the number of skilled expatriates in a subsidiary, the more the knowledge that can be transferred.

Several studies cited in Riusala and Smale (2007) suggest that relational factors between the parent and subsidiary companies can influence individual employees' interactions and relations, and hence impact on knowledge transfer. These so-called relational factors have also been interpreted in terms of local and organizational culture and socialisation (Smith 2004). Musasizi (2010) uses the concept of 'interaction adjustment' to refer to expatriate's ability to adapt to the local employees' way of relating and thus to interact effectively. Shaffer, Harrison and Gilley (1999) cited in Musasizi (2010) found that support from supervisors and co-workers influenced 'interaction adjustment', expatriate adaptability, and hence knowledge transfer. Socialization may also be related to the internal social capital dimension of IC theory. In this regard, Muneer (2011) observes that expatriates who are fully utilized and better able to transfer knowledge to locals which can then be developed into social capital; hence serving to eliminate human resources scarcity. However, Riusala and Smale (2010) did not find statistically significant effects of relational factors such as trust in and identification with the parent organization on knowledge transfer from expatriates to locals.

\section{RESEARCH METHODOLOGY}

This study was prompted by a concern with the organizations use of expatriates to bridge the skills gap on Project X, and their role in knowledge transfer. Other research issues include the local employees' perceptions of organizational support of knowledge sharing, the effectiveness of training programmes and hence the formulation of an appropriate long term knowledge management policy for the organization. Quantitative data was collected using a questionnaire followed by semi-structured interviews with selected personnel.

\subsection{The Research Instrument}

A questionnaire was developed by the researcher to explore the issues underlying this study. It consisted of three sections, viz. Section A, which gathered respondents' biographical information, Section B which examined opinions on the nature and causes of the skills shortages experienced on the Project, and the employment of expatriates, and Section $\mathrm{C}$ which elicited opinions on organizational climate and support of knowledge transfer. Sections B and C comprised 20 items.

The questionnaire was pre-tested on 5 individuals who matched the profile of the sample, and who were also working on Project $\mathrm{X}$ at the time. Factors such as managerial and peer support, which were important 
components of organizational capital (OC) in Kaplan and Norton's (2004) model are included in the questionnaire. Criterion validity is gauged by comparing the responses on the questionnaire to those obtained during the interviews since very similar issues were probed. Finally, the responses to items on the energy utility's support of skills development reflect the primary construct of knowledge transfer, i.e. knowledge transfer will be successful if the organizational climate, a key aspect in Kaplan and Norton's (2004) model, is conducive to knowledge sharing.

Reliability analysis using the SPSS software, yielded a Cronbach's alpha value of 0.12 for Section B and 0.81 for Section C. The low reliability for Section B is attributable to several factors: the construct is newly devised and there was no precedent in the literature that captured the multifaceted research questions; the number of statements for the sub-themes are not sufficient; and most important, respondents identified multiple sub-themes due to the underlying tensions and unspoken issues relating to the use of expatriates on the Project. Communalities for Section B were of a generally acceptable level ranging from 0.57 to 0.85 for the 9 items indicating relevance for the section. Nonetheless, results deriving from Section B cannot be generalised and must be interpreted with caution.

\subsection{The Sample}

The sample comprised skilled personnel who are directly involved on Project X. In this study "skilled" personnel are those possessing a three year tertiary qualification and at least 2 years' experience in the construction industry. Questionnaires were distributed to 70 such individuals over the period $15^{\text {th }}$ to $30^{\text {th }}$ May 2013. Approximately $20 \%$ of these personnel are expatriates. The response rate was approximately $69 \%$. Follow-up interviews were conducted with two expatriate and three local personnel during July 2013. Table 1 below describes the sample composition.

Table 1: Sample Demographics

\begin{tabular}{lcc}
\hline & Frequency & Percentage Of Sample \\
\hline Gender: & 37 & 77.1 \\
Male & 11 & 22.9 \\
Female & & 16.7 \\
\hline Age (years): & 8 & 37.5 \\
30 and below & 18 & 27.1 \\
$31-40$ & 13 & 10.4 \\
$41-50$ & 5 & 8.3 \\
$51-60$ & 4 & 89.6 \\
61 and above & & 10.4 \\
\hline Nationality: & 43 & 37.5 \\
South African & 5 & 43.8 \\
Foreign & & 18.8 \\
\hline Race: & 18 & \\
Black & 21 & \\
White & 9 & \\
Indian & & \\
\hline
\end{tabular}

Most of these participants have a technical background and hold an engineering qualification; others, such as human resources personnel were selected based on their experience in knowledge transfer and management. Hence, the sample was purposively selected in line with Kaplan and Norton's (2004) concept of "job families", i.e. key employees/teams. South African males comprise the majority of the sample at 67\%. Amongst the South African personnel, $44 \%$ are Black, $38 \%$ are White and the rest are Indian. Over half the sample is younger than 40 years. Table 2 provides data on the broad job categories of the participants, viz. Management, Technical and Other. 
Table 2: Job Categories

\begin{tabular}{lcc}
\hline Job category & Frequency & Percentage of sample \\
\hline Management & 17 & 35 \\
Technical & 23 & 48 \\
Other & 8 & 17 \\
\hline
\end{tabular}

Management personnel include Lead Discipline Managers (4\%), Project Package Managers (17\%), Risk Managers (2\%) and Engineering Managers (12\%). The Lead Discipline Manager (LDM) holds one of the most senior management positions on the Project and is responsible for the execution of the works from a construction perspective. The literature review has indicated the important role that management plays in knowledge transfer. Both the LDMs in this study are South African and 4 of the 5 expatriates were working in management roles. Technical personnel include engineers, quantity surveyors and supervisors who are directly responsible for the various activities required to "get the job done". The category "Other" comprise human resources personnel.

A wide range of construction experience characterises the sample. Twenty-nine percent of the sample are fairly new to construction with less than 5 years' experience, $31 \%$ have between 5 and 10 years, and $6 \%$ have between 10 and 15 years' experience. All the LDMs in the sample have at least 10 years construction experience. Since power station construction is a highly specialised activity, experience on Project $\mathrm{X}$ itself may lend more weight to an individual's opinions on the issues explored in this research. Over half (56\%) of the respondents report $2-4$ years' experience and about 31\% have been working for more than 4 years on the project. Forty percent of the expatriates in the sample have less than 2 years project-related experience and $20 \%$ have $2-4$ years' experience.

The nature of one's employment, i.e. permanent or contractual, may influence willingness to share knowledge as one may surmise that contract workers feel less loyalty to the organization, its human resources and its future growth. Twenty-nine percent of the overall sample and $100 \%$ of the expatriates are contract personnel. One may also argue that key personnel should ideally be appointed on a permanent basis to ensure continuity and stability. In this study, $29 \%$ of the personnel who held management positions and $26 \%$ of the technically-oriented personnel are on contract.

\section{ANALYSIS OF RESULTS ${ }^{1}$}

\subsection{Skills Issues and the Employment of Expatriates}

Table 3 below is a summary of the responses to the statements in Section B that deals with skills issues on the Project.

Table 3: Perceptions of Skills Issues

\begin{tabular}{|c|c|c|c|}
\hline & $\begin{array}{c}\text { Strongly } \\
\text { Agree/Agree }\end{array}$ & Neutral & $\begin{array}{c}\text { Strongly Disagree/ } \\
\text { Disagree }\end{array}$ \\
\hline $\begin{array}{l}\text { In terms of meeting the objectives of Project } X \text {, the necessary core } \\
\text { and critical skills employed on the project are sufficient.* }\end{array}$ & 47.9 & 16.6 & 35.4 \\
\hline The skills on the Project are properly utilized.* & 12.5 & 14.6 & 72.9 \\
\hline The Project objectives are directly linked to the skills requirements.* & 27.0 & 33.1 & 39.5 \\
\hline $\begin{array}{l}\text { In terms of meeting the Project objectives, the necessary core and } \\
\text { critical skills are available locally.* }\end{array}$ & 56.25 & 6.2 & 37.5 \\
\hline $\begin{array}{l}\text { Critical skills required on the Project are easily sourced from the } \\
\text { current skills resource pool available locally.* }\end{array}$ & 27.0 & 18.75 & 54.1 \\
\hline Expats largely contribute to the skills needed on the Project.* & 43.7 & 18.75 & 37.5 \\
\hline $\begin{array}{l}\text { Expats are adequately skilled to transfer skills needed by the Project } \\
\text { staff.* }\end{array}$ & 20.9 & 25 & 54.2 \\
\hline Skills are the key cause of delays on the Project. ${ }^{* *}$ & 41.6 & 8.3 & 50 \\
\hline $\begin{array}{l}\text { Mismatched / Less skilled employees are taking responsibility for the } \\
\text { Project outputs.** }\end{array}$ & 54.1 & 22.9 & 22.9 \\
\hline
\end{tabular}

${ }^{1}$ Results are statistically significant at the $99 \%(*)$ or $95 \%(* *)$ levels. 
In general, almost half the respondents in the study believed that the critical skills were sufficient but more than three-quarters felt that these skills were not being correctly utilized. In terms of skills availability $56.2 \%$ of the sample believed that skills were available locally, yet almost the same percentage argued that they were not easily sourced, implying competition between the public and private sectors for scarce engineering skills. Almost half the total sample (54.2\%), all local employees, believed that the foreigners were not able to transfer skills and knowledge. To the extent that this is true, it clearly negates the organization's rationale for hiring expatriates. Race played a statistically significant role in the responses to the statement on expatriates' ability to transfer skills. Over $70 \%$ of the Black respondents and $67 \%$ of the Indian respondents disagreed with this statement. The finding that $54 \%$ of the sample believes that less skilled individuals are taking responsibility for Project outputs implies a lack of faith in those holding key positions in terms of Project deliverables. At the same time half the sample are of the opinion that skills are not the major cause of delays on the Project, indicating that there are many complex issues at play.

Individual interviews were conducted with four of the local employees and two of the expatriates. In general, locals described the working relationship with expatriates as cordial but fairly formal. There was a perception that expatriates were not accustomed to the organization's way of doing things and some were not willing to concede or compromise. There was some indication that expatriates were not open to sharing knowledge.

The following are some of the responses to the question, "How would you describe your working relationship with foreigners?"

Local employee A:

... the difficulty that we have working with foreigners is that ... they want to do what they want to do. They do not want to be restricted by the organization policies and procedures and processes that govern the relationship ... so the relationship is fine if the recipient ...of your service is happy to follow the organizations' due process. If they are not happy with that, then it creates tension.

Local employee B:

I have found that if you do ask them to the face they answer you but they wouldn't tell you more than what you asked.

Local employee C:

I have worked with foreign workers and the relationship had been quite good but there was quite a lot of hidden information in the expat and they couldn't release everything that they know ... and moreso if you know things that they don't know, they wouldn't want to be seen that they don't know things.

The rationale for employing expatriates was to close the skills gap in the short term and deliver the Project. As indicated in the literature, there is often a long term strategic purpose to replace the foreigners with the locals who have acquired the skills and knowledge as a result of working with the expatriates. However, some of the responses by locals to the question, "Do you think the local employees are learning/acquiring skills by working with the foreigners? Why?" casts doubt on this knowledge management strategy and the assumption of unidirectional knowledge transfer from expatriates to locals.

Local employee A:

In [Division identity withheld] about 6 months ago we did a proper skill and knowledge transfer analysis and we had to give the portfolio committee feedback on what we have done from a skills and knowledge point of view ... I think less than 100 people benefitted ... So acquiring skills by working with the foreigners I think is a huge gap for improvement there, we haven't done it very well. 
Local employee C:

I believe that we are telling the foreigners what's going to be wrong with their decisions. There hasn't been much which they have been transferring to us. In actual fact we had to help them to make them understand how a power station is to be constructed. They didn't work in power stations ... and some of these guys don't have the aptitude or ability ... very few that I have seen actually transferred any skills to us. If I look back now, I cannot say any of the foreigners have transferred skills to me.

From the above, it appears that locals are transferring explicit knowledge to the expatriates, and there is very little sharing of tacit knowledge between both groups. Local perception is that the foreigners consider locals as unskilled and inept. Moreover, if locals do not have confidence and faith in the competence of the expatriates, minimal knowledge transfer will take place. However, one local was supportive of knowledge sharing by certain expatriates:

Local employee D:

I don't think they (i.e. locals) are learning because once again the foreigners themselves are here to learn our way of doing it and typically some foreigners tend to hide information. Typically some foreigners tend to have barriers in terms of how they can translate what they want to say ... Yes you do find individuals who are willing to go an extra mile. The [identity withheld] guys that will actually teach you like the [identity withheld] of this world who will be able to assist and teach you ... but once again it's only certain individuals that who will actually do that.

National culture and norms and communication were identified as barriers to building relationships (Kaplan and Norton's "social capital") on both sides. This was also flagged as a possible reason why expatriates may have been seen as not adequately equipped to transfer knowledge as indicated by the following responses:

Expatriate E:

The cultural difference is a key issue, eleven national languages and English is number five on the list. The expats have the skill but the issue is the communication of the skill to locals.

Expatriate F:

I think that there is a cultural difference and nobody spent the time making sure that cultural difference and cultural training was done. We put people from all over the world in a room and somebody is going to offend somebody ... if you go out and look at [Country Y] in Wikipedia, it's going to tell you that [Country $Y]$ is a first world country that speaks English during business and has a republic for a government, all those are green flags for every company in the world to come do business. You get here and you realise there is eleven national languages, English is only the fifth most popular language spoken in a home and there are as many cultural differences in the country between blacks, whites, coloureds and Indians. In those groups there are dislikes and likes, now take somebody from England and send them here, they won't have a clue of what's going on, they don't understand it ... is it obvious to you the South African if that person has the skill or they are able to communicate the skill? I think that is the biggest question, can that skill be communicated because what I have seen from multiple people expats is that they are skilled and they understand ... Has that expat been put in a position to use their skills properly ...I would suggest that you go back and ask the locals specifically if they felt that there was a communication barrier or cultural barrier because that's something you want to go and investigate. 
Local employee D:

It's become difficult for them example, there is the company in UK and USA, there is politics amongst the European and Americans, that's the first barrier that these guys have to go through. Then they actually force themselves to pretend as if they understand each other and trying to harvest our culture which becomes more difficult for them. The language barrier becomes a problem, the leadership skills become difficult, the translation becomes a difficulty on how they actually can do things here ...hence there are delays on the project and lack of skills transfer and hence these guys cannot assist us.

The same employee acknowledges that working with foreigners and cultural differences can have benefits, namely:

I have benefitted a lot maybe because I have worked with foreigners before. You end up learning the different cultures from their side how they do things in their own country. You end up understanding how in terms of execution, they execute a project.

The employment of expatriates as contract workers was not an issue raised in the literature since the empirical context tended to be private multinational organizations. However, in this study employing both expatriate and local contractors is identified as a significant factor impeding knowledge transfer for various reasons including high staff turnover, lack of motivation, lack of loyalty to the organization etc. as suggested in the responses below:

Local employee A:

if you just look at the foreign nationals that we have recruited on a fixed term contract basis ... the relationship that we have built with them over the last 5 years and now having to go back to them and say listen you must go back home, I think it is very bad. I don't think we have treated them well.

Local employee D:

In my opinion the joint venture company is acting like an agent of a labour broker, they actually pick up people from all over the show and they are mainly contract workers ...they are just here to make money and move on ... and hence we suffer the same consequences as the organization that we got people that are learning doing things for us, in other words the expats come and learn from us, once they have learnt they actually leave and we don't have nothing ... (staff turnover) is high ... and every 12 months you get a new guy coming in. This goes back to the leadership skills on the project because whoever they bring they will come and command the South Africans... Once you get used to the system 6 months down the line the guy is leaving and another guy comes in.

Local employee C:

... the expat is a high turnover and we must remember that they come for 6 weeks and they are off for 2 weeks so you don't have that constant continuity whereas we are required to stay there every week, every day permanently on site ... But in terms of the individuals, as soon as you got on your CV 2 years of experience at Project X, irrespective whether you did 0 or 100\%, people think that this guy is coming from Project X. So you have a high turnover and I don't think that there is consistency with management as well, because if you look along the 3 year line... I think they have been through 6 or 7 site managers now. If you just look at that there is no continuity even with site managers.

\subsection{Organizational Support of Knowledge Transfer}

Table 4 below is a summary of the responses to the statements in the questionnaire dealing with organizational commitment and support to knowledge transfer based on relationships between managers and subordinates, and between peers themselves, as well as the efficacy of the organization's HRM training mechanisms and procedures. 
Table 4: Perceptions of Organizational Support of Knowledge Transfer

\begin{tabular}{|c|c|c|c|}
\hline & $\begin{array}{c}\text { Strongly } \\
\text { Agree/Agree }\end{array}$ & Neutral & $\begin{array}{c}\text { Strongly Disagree/ } \\
\text { Disagree }\end{array}$ \\
\hline $\begin{array}{l}\text { Senior Management within the project is supportive of training for } \\
\text { employees on Project X.* }\end{array}$ & 56.3 & 20.8 & 22.9 \\
\hline $\begin{array}{l}\text { My immediate Line Manager is supportive of training for me on } \\
\text { the Project.* }\end{array}$ & 57.4 & 14.9 & 27.7 \\
\hline $\begin{array}{l}\text { Senior Management within the Project provides an enabling work } \\
\text { environment for the use of new skills.* }\end{array}$ & 25.5 & 42.6 & 31.9 \\
\hline $\begin{array}{l}\text { My immediate Line Manager provides an enabling work } \\
\text { environment for me to } 337 \text { ateria the use of new skills I have } \\
\text { learnt.* }\end{array}$ & 53.2 & 23.4 & 23.4 \\
\hline $\begin{array}{l}\text { My colleagues encourage me to use the skills I have learned in } \\
\text { training on the Project.* }\end{array}$ & 52.2 & 36.2 & 10.6 \\
\hline $\begin{array}{l}\text { My immediate Line Manager sets goals for me that encourage me } \\
\text { to apply my training when working on the Project.* }\end{array}$ & 29.2 & 27.1 & 43.8 \\
\hline Peer support is crucial for the learning and use of new skills.* & 87.5 & 8.3 & 4.2 \\
\hline My experienced peers and colleagues are of a foreign nationality & 31.3 & 18.8 & 50 \\
\hline $\begin{array}{l}\text { Project } \mathrm{X} \text { provides an enabling environment for skills transfer and } \\
\text { learning.* }\end{array}$ & 31.3 & 33.3 & 35.4 \\
\hline $\begin{array}{l}\text { The organization's recruitment policy supports fast and efficient } \\
\text { employment of staff.* }\end{array}$ & 2.1 & 25.0 & 72.9 \\
\hline Project X Training system (if in use) supports skills transfer.* & 14.9 & 38.3 & 46.8 \\
\hline
\end{tabular}

The majority of the sample tended to agree that management was supportive of training, with relatively more support being provided by immediate Line Management (57.4\%) relative to Senior Management (56.3\%). Studies by Sandhu et al. (2011) and Yao et al. (2007) identified management support as an important factor in knowledge transfer within the public sector. However, there is a clear disjuncture between support of skills transfer and the provision of a work environment that is conducive to applying the knowledge acquired. So the issue is whether management is perceived to pay lip service to learning and skills transfer, but do not follow through by providing the enabling environment to apply and hence internalise new knowledge. Also problematic is the result that $43.8 \%$ of the sample disagree that immediate line management set goals that encourage the application of new knowledge acquired. The fact that only 31.3\% agree that the Project environment itself is conducive to learning indicates that transfer and management of knowledge within the organization are not taking place effectively.

Almost $88 \%$ of respondents believe that their peers play a significant role in learning and applying new skills implying that relational capital is particularly important in this study. However, over half of the locals disagree that their expatriate colleagues are a means of knowledge transfer. Tacit knowledge in particular is embedded in work experience, and to the extent that expatriates are employed to transfer knowledge in the long term, this result is of concern. Further, the finding that the majority of locals do not believe the expatriates are adequately skilled (Section A) to transfer knowledge implies a lack of confidence on the part of locals in the abilities of the expatriate "experts" yet this has been found to be important in knowledge transfer (Bjorkman and Schapp 1994). It also casts doubt on the assumption of a unidirectional transfer of knowledge and skills from expatriates to locals that appears to premise the organization's current knowledge management policy (Miesing et al. 2004).

Finally, the results for Section $\mathrm{C}$ indicate that the vast majority of respondents do not have faith in the Project X Training System (PTS) as a vehicle for knowledge and skills transfer. The PTS is documented in the organization's Internal Training Procedure (Organization PPZ 200 - 49029). It is a procedure that caters for all training needs on the Project. Yet many of the respondents were not even aware of its existence. There was also significant 337aterializ in the organization's recruitment policy, e.g. $72.9 \%$ disagree that the policy enables fast and efficient employment of staff.

Given the important role played by organizational training systems within an overall knowledge management policy, an open-ended question was included, viz. "Do you think that new skills acquired by an employee through the Project X Training System are relevant and can be effectively 337aterial on the Project?" 
Approximately $85 \%$ of the respondents indicated that either this was not the case or they were not aware of the training system. Some of the comments made for or against the PTS are listed in Table 5 below.

Table 5: Effectiveness of the Project X Training System

\begin{tabular}{cl}
\hline Effective because: \\
- Linked to IDP (Individual Development Plan) \\
Ineffective because: \\
- Opportunity should be given to apply skills \\
- Not aware of training system \\
- Skills should be linked to job profiles \\
- Norking in silos and not sharing information \\
- No commitment by individuals \\
- Used for stats purpose only, not meaningful \\
\hline
\end{tabular}

Regarding the effectiveness of the PTS, the majority of the respondents commented that there is no time on the Project to train staff, since it is a fast track project and the schedule deadlines are extremely tight. Hence in practice, there is limited time and opportunity to apply skills, impeding effective knowledge transfer. One of the positive responses was that the PTS is aligned with the Individual Development Plan (IDP) that defines all the training requirements of the individual employees. The execution of the training requirements is done through the PTS.

\section{MANAGERIAL RECOMMENDATIONS}

As discussed earlier, an MNC is the joint venture partner with the energy utility in the execution of Project X. The energy utility's HRM policy has a "skills and knowledge transfer procedure" (Organization PPZ265-92), compiled specifically for the Capital Expansion Department (CED), which is directly responsible for the execution of Project X. This procedure states that skills should be transferred between contractors and the organization and that the contractors supplying skilled resources for the project shall be accountable for skills and knowledge transfer in all phases of the project.

There are two aspects pertaining to knowledge transfer in the procedure stated below:

"Knowledge transfer shall include the process of moving a body of knowledge or ideas from contract resources and organization (e.g. consultants) to the organization and its employees working on Build Programme or project through individuals, processes and technology, while skills transfer shall particularly cover the process by which specific experience and skills in a particular individual are transferred to one or more individuals who are less experienced".

This procedure therefore confirms that the joint venture company in its role as a major contractor on the Project, is required to transfer knowledge and skills to the organization's employees. Moreover, the procedure relates to the concepts of explicit and tacit knowledge. The explicit knowledge refers to ideas and content know-how of the MNC and its personnel whilst tacit knowledge refers to the experience and specific skills of the MNC's employees being transferred to the energy utility's local employees.

The results of the study indicate that skills transfer is not occurring. One of the respondents confirmed in the interview that everything is good on paper, but when it comes to executing these procedures nothing 338aterializes thus making skills transfer not achievable. It is therefore recommended that the contractual obligation of contractors to transfer knowledge and skills be enforced. For example, contractors could run formal training programmes where necessary or the more tacit on-the-job knowledge transfer be monitored by the organization's management. Financial and other penalties could be levied if contractual obligations are not being met. Further, local employees should be surveyed regularly to verify whether and to what extent knowledge transfer is actually occurring. However, a limitation of this strategy in the current context is that Project X has been placed on a "fast track" status and thus there is very little (or no) time for formal knowledge transfer initiatives. 
Another respondent stated that whilst the immediate line manager supported the use of new skills on the project, the senior management frequently did not (Table 4). Project $\mathrm{X}$ is complex and there are many levels of management within the project. The training courses approved by the line manager do not guarantee final approval as the senior manager has this authority. However, in most cases, it is the line manager who has the "on the floor" experience to know the skills and knowledge "gaps" in his/her team. It is therefore recommended that senior management does not have absolute veto power regarding training programmes promoted by line management and that an arbitration process be initiated in instances where disagreement occurs.

Some of the expatriates in the study confirmed that culture was a major barrier in the transferring of knowledge particularly because of the variety of cultures and languages within the country. It is recommended that all foreigners working on future projects be required to spend some time with the locals (for example in host families) to learn and understand the local culture. The organization as an employer can also assist in this regard by hosting social gatherings outside the work environment whereby a cordial relationship between expatriates and locals may be developed. The contracting firm may additionally be required to provide appropriate "culture training" to their personnel before deployment to the host country.

A frequent comment made by the locals in this study is that many of the expatriates are working on the Project to learn from the locals, rather than being the "experts" who are employed to bridge the skills gap and transfer knowledge to the local employees. This is allegedly because some of the expats have not worked on a power plant previously. Furthermore, the expatriates were afraid to admit that they were learning from the locals. These allegations regarding the skills and experience of the expatriates are difficult to verify since HR records are confidential. However, the fact that several of the local respondents in this study have expressed such comments is disquieting. Stricter control is to be enforced by the organization's HR to ensure that the contractor partner supplies appropriately skilled and experienced personnel and that these qualifications are verified in advance.

\section{CONCLUSION}

The little research that has been done on the role of expatriates in knowledge transfer within the public sector tends to be located in public administration and government departments rather than SOEs. Within the HRM context, interest in expatriate knowledge transfer has led to the emergence of a new field, global talent management (Tarique and Schuler 2013). The concept of talent management resonates with the objectives of the current research, the results of which suggest that knowledge transfer from expatriates to local employees has been less successful than envisaged by the organization; hence the existing local talent has not been cultivated nor managed appropriately, casting doubt on the long term success of the HRM strategy. Existing research suggests that one of the reasons for poor service delivery in Africa is inappropriate talent management within the public sector (Koketso and Rust 2011). There is sufficient evidence in the literature on global talent management to suggest that host country HR practices including country culture do impact on the efficacy of knowledge transfer (Tarique and Schuler 2013) and the results of this study bear support. The crucial role played by senior management and the importance of local employees' "faith" in the skills and knowledge of the expatriates were also found to be important determinants of knowledge transfer in this study.

\section{ACKNOWLEDGEMENTS}

The identity of the energy utility has been withheld at the organization's request as construction of the power plant is ongoing. The authors wish to acknowledge the helpful comments provided by Prof. Hamanth Kasan on earlier drafts of this paper.

\section{AUTHOR INFORMATION}

Sunny Ravu is employed as a Chief Advisor at a leading energy utility in Africa. He completed a Master's Degree in Project Management at the University of Kwa-Zulu Natal. He has worked on various power station projects. His interests are Project Management with specific interests in the contractual and planning aspects of the project. Email: Sunny.ravu.sr@gmail.com (Contact author) 
Kudayja Parker is a Senior Lecturer in Economics in the Department of Public Management and Economics at the Durban University of Technology. She completed doctoral studies in the United States under the supervision of Prof. William B. Walstad. Her primary research interests encompass Development Economics, Economics Education and the Economics of Education. She has a keen interest in economic literacy and the determinants of student achievement, at both the undergraduate and postgraduate levels of study. E-mail: koo@ dut.ac.za

\section{REFERENCES}

Ahmad, H.S., Sharom, N. and Abdullah, C.S. (publication date unknown). Knowledge sharing behaviour in the public sector: The business management perspectives. Retrieved from http://repo.uum.edu.my.

Al-Karaghouli, W., Alshawi, S. and Fitzgerald, G. (2005). Promoting requirement identification quality: Enhancing the human interaction dimension. Journal of Enterprise Information Management, 18(2) 256-67.

Awang-Rozaimie, A., Sahari, S. and Ali, A.J. (2012). Toward harmonious urban communities from the inside out: Validating a multicultural awareness scale. Procedia - Social and Behavioural Sciences, 36 732-741.

Bjorkman, I. and Schapp, A. (1994). Outsiders in the middle kingdom: Expatriate managers in Chinese-Western joint ventures. European Management Journal, 12(2) 147-153.

Bonache, J. and Brewster, C. (2001). Knowledge, transfer and the management of expatriation. Thunderbird International Business Review, 43(1) 145-168.

Bontis, N. (1996). There's a price on your head: Managing intellectual capital strategically. Business Quarterly, 60(4).

Cong, X. and Pandya, K.V. (2003). Issues of knowledge management in the public Sector. Electronic Journal of Knowledge Management, 1(2) 25-33 (accessed 23-09-2013)

Delios, A. and Bjorkman, I. (2000). Expatriates staffing in foreign subsidiaries of Japanese multinational corporations in the PRC and the United States. International Journal of Human Resource Management, 11(2) 278-293.

Edström, A. and Galbraith, J.R. (1977a). Transfer of managers as a control and coordination strategy in multinational organizations. Administrative Science Quarterly, 22 11-22.

Edvinsson, L. (1997). Developing intellectual capital at Skandia. Long Range Planning, 30(3) 366-373.

Gaunt. C. T. (2005). Meeting electrification's social objectives in Country, and implications for developing countries. Energy policy, 3 1309-1317.

Global Relocation Trends Survey Report (GRTS), 2012. Retrieved from http://espritgloballearning.com/wpcontent/uploads/2011/03/2012-Brookfield-Global-Relocations-Trends-Survey.pdf. (Accessed 03-10-2013)

Goh, S.C. (2002). Managing effective knowledge transfer: an integrative framework and some practice implication. Journal of Knowledge Management, 6(1) 23-30.

Gupta, A.K. and Govindarajan, V. (2000). Knowledge flows within multinational corporations. Strategic Management Journal, 21 473-496.

Gupta, B., Iyer, L. and Aronson, J.E. (2000). Knowledge management: practices and challenges. Industrial Management + Data Systems, 100(1) 17-21.

Hocking, JB, Brown, M and Harzing A (2004). A knowledge transfer perspective of strategic assignment purposes and their path-dependent outcomes. International Journal of Human Resource Management, 15 (3) 565586.

Kaplan, R.S. and Norton, D.P. (1992). The balanced scorecard measures that drive performance. Harvard Business Review, 70(1) 71-79.

Kaplan, R.S. and Norton, D.P. (2004). Measuring the strategic readiness of intangible assets. Harvard Business Review, 82(2) 52-63.

Kok, J.A. (2005). The internationalization of universities through the management of their intellectual capital: Managing the process of globalisation in new and upcoming EU members. 6th International Conference of the Faculty of Management Koper Congress Centre, 24-26 November 2005. Bernardin, Slovenia, 381-389.

Koketso, L. P. and Rust, A. B. (2012). Perceived challenges to talent management in the Countryn public service: An exploratory study of the City of Cape Town municipality. African Journal of Business Management, 6(6) 2221-2223.

Kraimer, M. L., Wayne, S. J., and Jaworski, R. A. (2001). Sources of support and expatriate performance: The mediating role of expatriate adjustment. Personnel Psychology, 54 71-100. 
Leana, C.R. and van Buren III, H.J. (1999). Organizational social capital and employment practices. Academy of Management Review, 24(3) 538-555.

Liebowitz, J. and Chen, Y. (2003). Knowledge sharing proficiencies: the key to knowledge management, in Holsapple, C.W. (Ed.) Handbook on Knowledge Management 1: Knowledge Matters, Springer-Verlag, Berlin, pp. 409-24.

Martin, K. (2003). Evaluating the benefits of knowledge management. Modern Practice, April 2003.

McAdam, R. and McCreedy, S. (1999). A critical review of knowledge management models. The Learning Organization, 6(3) 91-100.

McAdam, R. and Reid, R. (2000). A comparison of public and private sector perceptions and use of know edge management. Journal of European Industrial Training, 24(6) 317-329.

Miesing, P., Kriger, M., and Slough, N. (2004). Towards a model of effective knowledge transfer within transnationals: The case of Chinese foreign invested enterprises. Retrieved from http://www.albany.edu/ pm157/research/JTT.pdf

Muneer, S.E.T. (2011). Transfer of knowledge through expatriates nationals (TOKTEN) as a gender sensitive development assistance modality in practical societies: An example from Kassala State, Eastern Sudan. Journal of the Saudi Society of Agricultural Sciences, 10 89-94.

Musasizi, Y. (2010). Expatriate capabilities, knowledge transfer, competitive advantage and financial performance of foreign direct investments in the Ugandan service sector. MBA. Makerere University.

Nahapiet, J. and Ghoshal, S. (1998). Social capital, intellectual capital and the organizational advantage. Academy of Management Review, 23(2) 242-266.

Ngongo, C., Christie, K., Holden, J., Ford, C. and Pett, C. (2013). Striving for excellence: Nuturing midwives skills in Freetown, Sierra Leone. Midwifery, 29 1230-1234

Nohria, N. and Ghoshal, S. (1997). The differentiated network: Organizing multinationals for value creation. San Francisco: Jossey-Bass Publishers.

Nonaka, I. (1991). The knowledge-creating company. Harvard Business Review, 69 (6) 96-104.

Reed, KK., Lubatkin, M. and Srinivasan, N. (2006). Proposing and testing an intellectual capital-based view of the firm. Journal of Management Studies, 43(4) 867-893.

Riusala, K. and Smale, A. (2007). Predicting stickiness factors in the international transfer of knowledge through expatriates. International Studies of Management and Organization, 37(3) 16-43.

Rogers, B. (1999) 'The Expatriates in China - A Dying Species?'. In Lee, J. (ed.) Localization in

China: Best Practice. Hong Kong: Euromoney.

Samet, K. (2013) Circular migration between the North and South: Effects on the source Southern economies. Procedia - Social and Behavioural Sciences, 93 225-242.

Sandhu M.S., Jain, K.K. and Ahmad, I.K. (2011). Knowledge sharing among public sector employees: evidence from Malaysia. International Journal of Public Sector Management, 24(3) 206-226.

Shaffer, M. A., Harrison, D. A., Gregersen, H., Black, J. S., and Ferzandi, L. A. (2006). You can take it with you: Individual differences and expatriate effectiveness. Journal of Applied Psychology, 91 109-125.

Smith, P.M. (2004). American expatriates: an inquiry examining knowledge transfer and acquisition. Ph.D. Capella University.

Country. Department of Energy. 2012. Revised Strategic Plan 2011/12 - 2015/2016. Pretoria: Government Printer.

Steensma, K. and Lyles, M.A. (2000). Explaining IJV survival in a transitional economy through social exchange and knowledge-based perspectives. Strategic Management Journal, 21(8) 831-852.

Steyn, L. 2013. 'Power Plant delayed: what went wrong'. Mail and Guardian, July 8: www.mg.co.za, Accessed 4 November 2013.

Sveiby, K.E. (2001). A knowledge-based theory of the firm to guide in strategy formulation. Journal of Intellectual Capital, 2(4) 344-58.

Syed-Ikhsan, S.O.M. and Rowland, F.R. (2004a). Knowledge management in a public organization: a study on the relationship between organizational elements and the performance of knowledge transfer. Journal of Knowledge Management, 8(2) 95-111.

Syed-lkhsan, S.O.M. and Rowland, F. (2004b). Benchmarking knowledge management in a public organization in Malaysia. Benchmarking: An International Journal, 1(1) 238-266.

Takeuchi, R (2010). A critical review of expatriate adjustment research through a multiple stakeholder view: Progress, emerging trends, and prospects. Journal of Management, 36(4) 1040-1064.

Tarique, I and Schuler, R. (2012). Global talent management literature review; White paper: SHRM Foundation. 
Tsang, E.W.K. (2001). Managerial learning in foreign-invested enterprises of China. Management International Review, 41(1) 29-51

Wang, P., Tong, T.W. and Koh, C.P. (2004). An integrated model of knowledge transfer from MNC parent to China subsidiary. Journal of World Business, 39 168-182.

Wong, C.S. and Law, K.S. (1999). Managing localization of human resources in the PRC: A practical Model. Journal of World Business, 34(1) 26-40.

Yao, L.J., Kam, T.H.Y. and Chan, S.H. (2007). Knowledge sharing in Asian public administration sector: the case of Hong Kong. Journal of Enterprise Information Management, 20 (1) 51-69. 